Abstracta Iranica Abstracta Iranica

Revue bibliographique pour le domaine irano-aryen

Volume 22 | 2001

Comptes rendus des publications de 1999

Islam and Gender. The Religious Debate in Contemporary Iran. Princeton, New Jersey, Princeton University Press, 1999, 305 p., bibliographie, index.

Azadeh Kian-Thiébault

(2) OpenEdition Journals

Édition électronique

URL : http://journals.openedition.org/abstractairanica/37353

DOI : $10.4000 /$ abstractairanica.37353

ISSN : 1961-960X

Éditeur :

CNRS (UMR 7528 Mondes iraniens et indiens), Éditions de l'IFRI

Édition imprimée

Date de publication : 15 mai 2001

ISSN : 0240-8910

Référence électronique

Azadeh Kian-Thiébault, «Islam and Gender. The Religious Debate in Contemporary Iran. Princeton, New Jersey, Princeton University Press, 1999, 305 p., bibliographie, index. », Abstracta Iranica [En ligne], Volume 22 | 2001, document 646, mis en ligne le 17 février 2010, consulté le 13 octobre 2020. URL http://journals.openedition.org/abstractairanica/37353; DOI : https://doi.org/10.4000/ abstractairanica.37353

Ce document a été généré automatiquement le 13 octobre 2020.

Tous droits réservés 


\title{
Islam and Gender. The Religious Debate in Contemporary Iran. Princeton, New Jersey, Princeton University Press, 1999, 305 p., bibliographie, index.
}

\author{
Azadeh Kian-Thiébault
}

L'ouvrage est fondé sur les entretiens menés par l'auteur avec plusieurs clercs chi'ites dans la ville sainte de Qom et l'étude textuelle de leurs ouvrages sur les femmes dans la jurisprudence islamique (feqh). Les différentes notions du genre dans la jurisprudence islamique et les moyens par lesquels les clercs iraniens tentent aujourd'hui de perpétuer, modifier, déconstruire et reconstruire ces notions constituent le thème principal de ce livre remarquable. L'auteur relate l'ethnographie de son engagement avec des textes et leurs auteurs en vue de provoquer d'autres femmes musulmanes à écrire sur leur propre engagement et trajectoire. L'ouvrage est divisé en trois parties qui présente chacune les trois perspectives principales concernant la question du genre au sein des écoles théologiques de Qom. La première partie présente et analyse la perspective cléricale prédominante dans le système théologique avant la révolution et connue sous le nom de jurisprudence traditionnelle. Les "traditionalistes" représentés, notamment, par l'Āyatollāh Ādarī-Qomī et l'Āyatollāh Madanī-Tabrīzī concluent à l'inégalité entre les sexes. La deuxième partie concerne la jurisprudence dynamique c'est-à-dire selon les clercs que l'auteur appelle néo-traditionalistes car ils sont impliqués dans la création du nouveau système, sans pour autant défier directement les pensées traditionnelles. Ces « néo-traditionalistes » dirigés notamment par le Grand Āyatollāh Yūsof Șāne'ī et représentés par les clercs rédacteurs du magazine féminin Payām-e zan (Le message des femmes) publié à Qom concluent à l'équilibre entre les sexes. La dernière partie enfin concerne «les modernistes » ou les tenants d'un nouveau discours émergent sur les femmes, profondément enraciné dans la šarīa mais fortement influencé aussi par les intellectuels religieux comme 'Abdolkarīm Sorūš qui se trouvent en dehors des écoles théologiques. Les «modernistes », représentés, notamment, par l'Ḥojjat ol-Eslām Seyyed Moḥsen 
Sa'îdzāde qui collabore à l'influent magazine féminin Zanān (Les femmes) concluent à l'égalité entre les sexes. Néanmoins, selon Mir-Hosseini ces perspectives ne sont pas inflexibles et les frontières entre elles ne sont pas étanches dans la mesure où le dialogue est établi entre leurs tenants qui s'interagissent et s'influencent. D'autant qu'ils ne sont pas exclusivement clercs ou du sexe masculin et que leurs arguments et concepts ne proviennent pas uniquement des sources islamiques.

INDEX

Thèmes : 16.1. Iran

\section{AUTEURS}

AZADEH KIAN-THIÉBAULT

CNRS - Paris 